OPEN ACCESS

Edited by: Tiziana Ramaci, Kore University of Enna, Italy

Reviewed by: Harsha Perera, University of Nevada, Las Vegas, United States Vincenzo Russo, Università IULM, Italy

*Correspondence: Ilaria Buonomo i.buonomo1@/umsa.it

Specialty section: This article was submitted to Organizational Psychology, a section of the journal

Frontiers in Psychology

Received: 04 February 2019 Accepted: 02 July 2019 Published: 17 July 2019

Citation:

Buonomo I, Fiorilli $C$ and Benevene P (2019) The Impact of Emotions and Hedonic Balance on Teachers' Self-Efficacy: Testing the Bouncing Back Effect of Positive Emotions. Front. Psychol. 10:1670. doi: 10.3389/fpsyg.2019.01670

\section{The Impact of Emotions and Hedonic Balance on Teachers' Self-Efficacy: Testing the Bouncing Back Effect of Positive Emotions}

\author{
Ilaria Buonomo*, Caterina Fiorilli and Paula Benevene \\ Department of Human Science, Libera Università Maria SS. Assunta, Rome, Italy
}

Emotions toward students (e.g., Chan, 2004) and professional role (e.g., O'Connor, 2008) impact teachers' self-efficacy (TSE) beliefs. The effect of positive emotions (PEs) can be explained by the broaden and build theory, stating that the higher the PEs individuals attribute to themselves, the higher the chance to build positive aspects of the self (Fredrickson, 2001). At the same time, negative emotions (NES) at school inversely influence TSE, reducing teachers' confidence (Chan, 2004). Furthermore, Fredrickson et al. (2000)'s studies inform about the bouncing back effect of PEs on the detrimental effects of NEs on self-efficacy. Starting from these considerations, this study (1) evaluated the bouncing back effect of PEs on negative ones, when predicting self-efficacy; (2) verified whether emotions toward professional role moderated the bouncing back effect. Self-efficacy and emotions in teaching (MESI, Moè et al., 2010) were measured. Two hundred and seventy-two Italian secondary school teachers ( $F=73 \%$ ) were involved. PEs toward students might act as buffering factors against the detrimental effect of NEs on self-efficacy $[F(2,270)=26.17$, $\left.P<0.001, R^{2}=0.199\right]$. Finally, emotions toward students and emotions toward professional role do not interact when predicting self-efficacy. The relationships with students seem to have an highly protective effect on teachers' mental health. At the same time, the perception of one's own role as detached from the teaching community may have a role in justifying the non-significant effect of emotions toward professional role in the model and shed new light on intervention objectives.

Keywords: teachers, self-efficacy, trait emotions, undoing effect, professional role

\section{INTRODUCTION}

Tschannen-Moran et al. (1998) defined teachers' self-efficacy (TSE) as the teacher's belief in his or her capability to organize and execute the actions required to successfully accomplish professional tasks in a specific context (Tschannen-Moran et al., 1998). Teacher beliefs about professional efficacy influence several aspects in the teaching-learning process, including classroom environment, student performance, and teacher practices (Goddard et al., 2007; Santisi et al., 2014; Zee and Koomen, 2016; Benevene et al., 2018; Granziera and Perera, 2019). Accordingly, teachers with low self-efficacy are at high risk for absenteeism, physical illness, and burnout (Zee and Koomen, 2016). Given the impact of TSE on school life, influencing factors should be 
individuated, to shed a new light on well-being promotion at school. Consistently with Bandura's (1986) social-cognitive theory, Tschannen-Moran et al. (1998) individuated four main sources for TSE: vicarious experiences, sense of mastery, verbal persuasion, and physiological and emotional arousal. At the same time, the authors considered physiological states and associated emotions as less effective in predicting TSE when compared to other sources. This is due to the fact that physiological states and emotions must be carefully attended to have an effect on TSE (Tschannen-Moran et al., 1998). Several studies have shown that, when workers attend their positive emotional experiences, their self-efficacy raise (Wright and Staw, 1999; Lyubomirsky et al., 2005; Tsai et al., 2007; Staw et al., 2008; O’Malley and Gregory, 2011; Xanthopoulou et al., 2012). Furthermore, current research suggests that teachers are aware of their emotional involvement in their job. More specifically, several authors show that teachers recognize the effects of emotions and relations experienced at school on their teaching goals, experiences, and results (Sutton and Wheatley, 2003; Sutton and Harper, 2009; Borrelli et al., 2014; Fiorilli et al., 2017). Consistently, some studies report that teachers who generally experiment more positive than negative emotions (NEs) feel more confident too (Sutton and Harper, 2009).

The effect of positive emotions (PEs) on self-efficacy can be read in light of the broaden and build theory, stating that the higher the PEs individuals attribute to themselves, the higher the chance to build positive aspects of the self (Fredrickson, 2001; Fredrickson and Losada, 2005). At the same time, teaching is loaded with NEs, too, for example because of student misbehavior or low social recognition (Becker et al., 2015; Mevarech and Maskit, 2015; Frenzel et al., 2016; Fiorilli et al., 2017). The emotional correlates of such problems and conflicts at school inversely influence TSE, reducing teachers' confidence (Chan, 2004). Therefore, it seems useful to take into account the cooccurrence between positive and NEs (Diener and Emmons, 1984), and how this may influence teacher self-efficacy.

Positive and NEs, indeed, activate different biological and behavioral patterns and are independently regulated over time (Diener et al., 1985; Watson, 2000).

How positive and NEs influence one another, when influencing self-efficacy? A possible explanation is provided by the construct of undoing effect (Fredrickson et al., 2000), interpreted as the ability of PEs to restore psychological resources in face of NEs and experiences (Gloria et al., 2013). When individuals make the most of their PEs, they are better at reducing the detrimental effects of negative affect on personal interpretations of events (Tugade and Fredrickson, 2004, 2007). Consistently, previous studies reported that positive affect mediated the relationship between NEs at work and psychological resources in teachers (Gloria et al., 2013). Recognizing PEs at work, indeed, could act as a buffer, through which the potential detrimental effect of NEs on self-efficacy would be lowered. Despite this, to the best of our knowledge, no studies have explored such effects on self-efficacy.

When studying teacher emotions, a distinction should be made between emotions toward students and emotions toward the teaching professional role (Moè et al., 2010). While many studies addressed the firsts, few studies addresses the seconds, despite showing meaningful implications for the profession (Sutton and Wheatley, 2003). More specifically, teachers' emotions toward their role guide their practices and shape their professional identities, independently from the actual teaching experience in the classroom ( $\mathrm{O}^{\prime}$ Connor, 2008; Gonzalez-Calvo and Arias-Carballal, 2017). In other words, emotions seem a crucial point of teachers' professional life. According to Palmer (1998), this is due to the fact that the teaching profession is at the crossroad of personal and public life. With this regard, teaching professional role involves two interacting dimensions: intrapersonal factors, such as emotions and personal history (e.g., Zembylas, 2003; Van Veen and Sleegers, 2006) and social factors, such as personal and professional relations and social representations about the profession (Holstein and Gubrium, 2000; Roa-Tampe, 2017). Teachers, indeed, spontaneously refer to emotions when asked to enumerate the main dimensions of their profession (Buonomo and Fatigante, 2017; Gonzalez-Calvo and AriasCarballal, 2017; González-Calvo and Fernández-Balboa, 2018). This broader "emotional context," connected with teachers' identities, influences emotions experienced with students during classroom interactions. O'Connor (2008), indeed, argued that teachers justify their caring attitude toward students as a main part of their professional identity. At the same time, current research suggests that teachers experience several NEs toward their professional role, above all related to low social recognition of their profession and feeling of social underestimation (OECD, 2014; Buonomo et al., 2017). Teachers able to balance the contrasting emotions felt toward professional role may be better at mitigating the detrimental effects of NEs on TSE, thus strengthening the protective impact of positive classroom experiences on their sense of confidence. The ability to balance positive and NEs (namely, hedonic balance; Diener et al., 1999) regarding the role, indeed, was related to efficacy beliefs in Italian teachers (Caprara and Steca, 2006).

Overall, emotions related to students and to the teaching role can be considered as distinct sources of information about teachers' emotional experiences. Generally speaking, the emotional acknowledgment at work predicts self-efficacy beliefs (e.g., Xanthopoulou et al., 2012). For this reason, we hypothesized that emotions toward students would explain teachers' selfefficacy. At the same time, as teachers' identities are embedded with emotions (O'Connor, 2008), we considered emotions toward professional role as generating a broader emotional context that could influence the predictive effects of emotions toward students. More specifically, this study aimed to verify two hypotheses:

Hypothesis 1 - positive emotions toward students mediate the detrimental effect of negative emotions toward students on self-efficacy;

Hypothesis 2 - hedonic balance related to professional role moderates the mediating effect of positive emotions, so that the higher the hedonic balance, the higher the mediating effect of positive emotions. 


\section{MATERIALS AND METHODS}

Participants were 272 Italian school teachers (Females $=73 \%$ ), aged 26-66 $(M=51.50 ; S D=7.96)$ years and with $1-$ 41 years of experience $(M=21.74 ; S D=10.37)$. The most of them were class $(91 \%)$ and permanent $(89 \%)$ teachers. Data collection occurred during school meetings, with principals' consent. Teachers were instructed by written informed consent that they could leave the study and ask for further information at any time. Teachers' self-efficacy and emotions were assessed with the Metacognitive Questionnaires for Teachers, validated on the Italian teaching population (MESI; Moè et al., 2010). Self-efficacy was measured with 24 -item, on a 10 -point Likert scale ( $1=$ not effective, 10 = totally effective) (sample item: "I am good at managing students' oppositional behaviors"). Teachers' PE and NE, toward students and professional role, were measured with 30 items ("how frequently do you feel these emotions when you are with your students/when you think about your profession?"), measured on a 5point Likert scale ( $1=$ almost never, $5=$ almost always). The subscale measured 17 NEs (shame, anger, uneasiness, inadequacy, wrath, exasperation, indignation, sadness, sense of failure, guilt, resignation, irritation, antipathy, frustration, discouragement, nervousness, disappointment) and 13 PEs (cheerfulness, enthusiasm, caring, commotion, admiration, complacency, pleasure, happiness, satisfaction, fulfilment, sense of accomplishment, joy, enrichment). NE and PE are computed as total mean scores of the answers to the 17 and 13 items, respectively (Moè et al., 2010). Starting from the scales of $\mathrm{PE}$ and $\mathrm{NE}$ toward the professional role, hedonic balance related to professional role was computed as the difference between PE and NE (Diener et al., 1999). Consequently, when the hedonic balance is high, the respondent perceives more PE than NE. Reliability was examined by estimating Cronbach's alpha and McDonald's omega (McDonald, 1999), as the last has been advocated as more informative than Cronbach's alpha (Revelle and Zinbarg, 2009), especially for heterogeneous scales. Omega is an indicator of general factor saturation, interpreted as the precision with which scale scores estimate a latent variable common to all test items. Overall, Cronbach's alphas ranged 0.835 (NE toward professional role) to 0.975 ( $\mathrm{PE}$ toward professional role), while McDonald's Omegas ranged from 0.92 (NE toward professional role and NEs toward students) to 0.95 (PE toward professional role).

The associations among self-efficacy, sociodemographic variables, student-related emotions, and role-related hedonic balance were calculated with Pearson's product-moment correlations. As sociodemographic variables did not correlate with other variables, these were not included in the analyses. Two multiple regression analyses were conducted: (1) Hypothesis 1 (PEs toward students mediate the detrimental effect of NEs toward students on self-efficacy) was verified with a mediation model, in which beta weights are used to measure direct and indirect effects and bootstrap method (5000 samples) is used to test the effect size of the indirect effect; (2) Hypothesis 2 (hedonic balance related to professional role moderates the mediating effect of PEs) was verified with the beta weight of the interaction between hedonic balance and PE toward students. Variables were mean centered prior to the formation of the interaction term (Aiken and West, 1991), to differentiate the moderating effect at low, medium, and high levels of hedonic balance. Predicted probability plots, residuals scatterplots, and variance inflation factor $(\mathrm{VIF})<5$, and Tolerance $>0.80$ criteria were used to test, respectively, the normality, homoscedasticity, and non-multicollinearity assumption for regression. All the variables for all the regression models fulfilled the assumptions. Finally, a $p>0.001$ Mahalanobis' distance criterion was used to identify and skip multivariate outliers. Analyses were run with the PROCESS macro (Hayes, 2012) for IBM SPSS (vr. 23) and with the psych package in R (vr. 3.5.3) (Revelle, 2016).

\section{RESULTS}

Table 1 shows mean and standard deviation values and correlations among self-efficacy, student-related PE and NE, and role-related hedonic balance. All the associations were significant $(p<0.01)$. Overall, the higher the PEs perceived with students, the higher the hedonic balance related to professional role, the higher the perceived self-efficacy.

Table 2 shows the simple mediation model. As expected (Hypothesis 1), student-related PEs mediated the relationship between student-related NEs and self-efficacy $\left[F_{(2,270)}=26.17\right.$, $\left.p<0.001, R^{2}=0.199\right]$. The effect of student-related NEs on self-efficacy was significant $[b=-0.4918, t(273)=-5.0161$, $p<0.001]$, as well as the effect of student-related PEs on selfefficacy $[b=0.3681, t(271)=3.73, p<0.001]$. The indirect effect was significant $(95 \% \mathrm{CI}=-0.292$ to -0.093 ; bootstrapped unstandardized indirect effect $=-0.161$, bootstrapping run on 5000 samples). Overall, results show a partial mediation of PEs in the relationship between NEs and self-efficacy.

Table 3 shows the moderated mediation model (or indirect conditional effect; Preacher et al., 2007). Contrarily to Hypothesis 2 , the role-related hedonic balance did not moderate the mediation of student-related PEs on the relationship between student-related NEs and self-efficacy [interaction effect was $b=-0.08, t(271)=-1.35, \mathrm{NS}]$.

\section{DISCUSSION}

Our findings showed that PEs toward students partially mediate the relationship between NEs toward students and self-efficacy in a sample of Italian teachers, confirming our first hypothesis. At the same time, our results showed that the hedonic balance toward professional role did not influence the effect of PEs on self-efficacy, contrarily to our second hypothesis.

Overall, this study confirmed the role of emotions in predicting teaching self-efficacy, strengthening socialcognitive theory statements about the role of emotional arousal in predicting efficacy beliefs (Bandura, 1986; Tschannen-Moran et al., 1998). 
TABLE 1 | Mean, standard deviations, and correlations among variables.

\begin{tabular}{|c|c|c|c|c|c|c|}
\hline & $M$ & $S D$ & Self-efficacy & $\begin{array}{c}\text { Student-related } \\
\text { negative } \\
\text { emotions(NEs) }\end{array}$ & $\begin{array}{c}\text { Student-related } \\
\text { positive emotions } \\
\text { (PEs) }\end{array}$ & $\begin{array}{l}\text { HB- } \\
\text { professional } \\
\text { role }\end{array}$ \\
\hline Self-efficacy & 7.28 & 0.89 & - & & & \\
\hline Student-related NEs & 1.70 & 0.51 & $-0.371^{* *}$ & - & & \\
\hline Student-related PEs & 3.60 & 0.64 & $0.361^{* *}$ & $-0.347^{* *}$ & - & \\
\hline HB-professional role & 1.58 & 1.13 & $0.337^{* *}$ & $-0.581^{* *}$ & $0.652^{* *}$ & - \\
\hline
\end{tabular}

${ }^{* *} p<0.01$. HB, hedonic balance.

TABLE 2 | Regression results for simple mediation.

\begin{tabular}{|c|c|c|c|c|}
\hline Variable & $B$ & SE & $t$ & $p$ \\
\hline \multicolumn{5}{|l|}{ Direct and total effects } \\
\hline Self-efficacy regressed on NEs toward students & -0.65 & 0.10 & -6.83 & 0.000 \\
\hline PEs toward students regressed on NEs toward students & -0.44 & 0.07 & -6.6 & 0.000 \\
\hline Self-efficacy regressed on PEs toward students controlling for NEs toward students & 0.37 & 0.10 & 0.37 & 0.000 \\
\hline \multirow[t]{2}{*}{ Self-efficacy regressed on NEs toward students controlling for PEs toward students } & -0.49 & 0.10 & -5.02 & 0.000 \\
\hline & Value & $S E$ & $z$ & $p$ \\
\hline \multicolumn{5}{|l|}{ Bootstrap results for indirect effect } \\
\hline Effect & -0.16 & 0.48 & -0.27 & -0.08 \\
\hline
\end{tabular}

Unstandardized regression coefficients are reported. Bootstrap sample size: 5000. LL, lower limit; Cl, confidence interval; UL, upper limit.

TABLE 3 | Regression results for conditional indirect effect.

\begin{tabular}{lrrrr}
\hline Predictor & $\boldsymbol{B}$ & $\boldsymbol{S E}$ & $\boldsymbol{t}$ & $\boldsymbol{p}$ \\
\hline PEs toward students & & & & \\
Constant & 0.75 & 0.13 & 5.85 & 0.000 \\
NEs toward students & -0.44 & 0.07 & -6.11 & 0.000 \\
Self-efficacy & & & & \\
Constant & 8.14 & 0.21 & 39.33 & 0.000 \\
PEs toward students (PEs) & 0.35 & 0.10 & 3.52 & 0.000 \\
NEs toward students (NEs) & -0.49 & 0.12 & -4.15 & 0.000 \\
Hedonic balance related to & 0.00 & 0.07 & 0.05 & 0.958 \\
professional role (HBpr) & & & & \\
PEs $\times$ HBpr & -0.08 & 0.06 & -1.35 & 0.179 \\
\hline
\end{tabular}

$N=272$. Unstandardized regression coefficients are reported. Bootstrap sample size: 5000.

According to our first hypothesis, when teachers frequently experience NEs toward their students, they are at higher risk for believing to be not effective in the classroom. Emotional labor is a possible explanation for this finding, as it may have influenced teachers' answers. Emotional labor is the strain emerging from the contrast between felt emotions and organizational rules about emotion expression (Schutz and Lee, 2014). In other words, teachers may feel they are not allowed to express certain emotions because of the school's rules about emotional disclosure (Yin and Lee, 2012). According to the emotional labor framework, indeed, the higher the emotions felt but not expressed, the higher the stress and burnout risk (Yin and Lee, 2012). At the same time, and contrarily to our results, other studies (Sutton and Harper, 2009) showed that teachers tend to express or fake anger toward their students in order to maintain discipline and that, by means of this strategy, they feel more effective at managing their classroom. To better understand these apparently contrasting results, the type of studied emotions should be considered. Studies about teachers' emotions, indeed, usually address basic NEs (Sutton and Harper, 2009; Yin and Lee, 2012). In our study, teachers answered about their complex, self-conscious emotions (e.g., sense of failure, guilt, resignation, frustration, discouragement; Tracy and Robins, 2007), linked to experiences of loss or blame (Thamm, 2006). This may explain the reduction of self-efficacy. Individuals with high negative self-conscious emotions, like blame, guilt, and discouragement, are at higher risk to experience low selfesteem (Kuppens and Van Mechelen, 2007). Therefore, it is likely that these emotions may have a role in reducing selfefficacy, too.

According to our first hypothesis, findings showed that PEs toward students partially protect teachers from detrimental effect of negative ones on self-efficacy. As reported by Llorens et al. (2007), positive emotional states may help workers perceiving themselves more efficacious in performing daily tasks at work. Moreover, according to the broaden and build theory and its applications at work (Tugade and Fredrickson, 2004, 2007; Gloria et al., 2013), PEs may restore psychological resources (e.g., self-efficacy) despite the acknowledgment of NEs. How teachers' PEs may have such a role? van der Want et al. (2018) stated that each teacher has a professional interpersonal standard, depending on personal beliefs and values, and related to the relationship with students. 
According to the authors, affective and cognitive appraisals about personal well-being and emotions and coping with stressful situations are represented accordingly to the interpersonal identity standards and guide teachers' experience and expression of emotions. Accordingly, we have found that teachers recursively make use of the garden metaphor, reporting to be emotionally refueled by their students' recognition (Buonomo and Fatigante, 2017). This point may clarify the bouncing back effect (Tugade and Fredrickson, 2004) found in this study: if teachers are willing to "accept" a contextual stressor, hoping to reach a more favorable outcome, then it is likely that PEs may help to build stronger efficacy beliefs regarding their teaching abilities.

Finally, contrarily to our second hypothesis, PEs toward professional role did not moderate the mediation effect shown in the study. This finding may be due to the characteristics of the Italian educational system itself. According to Bracci (2009), the web of accountability in Italian schools is getting confused because of several changes and reforms: in such a condition, it is likely that teachers take an individualistic point of view, giving more saliency and attention to the personal experience of teaching, than to the idea of being part of a specific group of professionals. Moreover, previous studies showed that being happy to be part of a school institution does not necessarily promote teachers' efficacy beliefs (Malinen and Savolainen, 2016; Buonomo et al., 2017).

Regarding the limitations of the study, the use of longitudinal data is needed, to better address the mediation effect, giving more robust support to the findings, as mediations on crosssectional data are known to be biased because of autoregressive effects (Maxwell and Cole, 2007). The impossibility to distinguish between "actual" predictors and results in cross-sectional designs (namely the impossibility to define a temporal lag between predictor and mediator, and mediator and outcome) weakens the inferences that can be made from our model. Moreover, the lack of a temporal lag didn't allow to verify whether, as reported from previous studies (Canrinus and Fokkens-Bruinsma, 2011; Rodríguez-Sánchez et al., 2011; Lohbeck et al., 2018), feeling effective as a teacher may have influenced the level of PE and $\mathrm{NE}$ experienced in the classroom. For example, indeed, previous studies acknowledged that teachers with high self-efficacy are more prone to experience PE than NE with students, and vice

\section{REFERENCES}

Aiken, L. S., and West, S. G. (1991). Multiple Regression: Testing and Interpreting Interactions. Thousand Oaks, PA: SAGE.

Bandura, A. (1986). The explanatory and predictive scope of self-efficacy theory. J. Soc. Clin. Psychol. 4, 359-373. doi: 10.1521/jscp.1986.4.3.359

Becker, E. S., Keller, M. M., Goetz, T., Frenzel, A. C., and Taxer, J. L. (2015). Antecedents of teachers' emotions in the classroom: an intraindividual approach. Front. Psychol. 6:635. doi: 10.3389/fpsyg.2015.00635

Benevene, P., Ittan, M. M., and Cortini, M. (2018). Self-esteem and happiness as predictors of school teachers' health: the mediating role of job satisfaction. Front. Psychol. 9:933. doi: 10.3389/fpsyg.2018.00933

Borrelli, I., Benevene, P., Fiorilli, C., D’Amelio, F., and Pozzi, G. (2014). Working conditions and mental health in teachers: a preliminary study. Occup. Med. 64, 530-532. doi: 10.1093/occmed/kqu108 versa (Tschannen-Moran et al., 1998). Furthermore, a distinction between the effects of trait- and state-emotions on self-efficacy should be done, as they differently impact teachers' professional experiences (Goetz et al., 2015). Finally, a multimethod approach would give more information on how teachers perceive their emotions and how emotional experiences impact self-efficacy (Sutton and Wheatley, 2003).

Despite these limitations, our study shed new light on the effect of emotions on self-efficacy in teachers and have some practical implications concerning teachers' training, regarding positive psychology interventions on school climate (Jennings and Greenberg, 2009). Improving teachers' abilities to acknowledge positive exchanges and experiences within the school context may heighten their abilities to recognize personal attainments and successes as professionals. Moreover, our study suggests taking into account the organizational dimension of the teaching profession when intervening on teaching communities. Cultivating collaboration and sense of community within schools, indeed, may strengthening the effect of PEs: from one side, by increasing PEs during daily school life (Jennings and Greenberg, 2009), from the other, by improving positive perceptions of the teaching profession.

\section{ETHICS STATEMENT}

The authors assert that all procedures contributing to this work comply with the ethical standards of the relevant national and institutional committees on human experimentation. All participants gave written informed consent in accordance with the Declaration of Helsinki. Ethical implications were evaluated by the Scientific Board of Libera Università Maria SS. Assunta (LUMSA), the body responsible for providing ethics approvals for studies, that approved the study.

\section{AUTHOR CONTRIBUTIONS}

IB designed and carried out the study. IB and CF contributed to the analysis of the results and to the writing of the manuscript. PB supervised the study design and the manuscript draft.

Bracci, E. (2009). Autonomy, responsibility and accountability in the Italian school system. Crit. Perspect. Account. 20, 293-312. doi: 10.1016/j.cpa.2008.09.001

Buonomo, I., and Fatigante, M. (2017). Effetto delle Relazioni nella Comunitá Scolastica sul Benessere Percepito degli Insegnanti [Effect of Relationship with Teaching Colleagues on Teacher Perceived Wellbeing]. Book of Abstracts of the 10th Italian Conference of Positive Psychology. Available at: http://www.psicologiapositiva.it/wp-content/uploads/2017/06/book_of_ abstracts_gnpp10.pdf (accessed July 2019).

Buonomo, I., Fatigante, M., and Fiorilli, C. (2017). The open psychology journal teachers' burnout profile: risk and protective factors. Open Psychol. J. 10, 190-201. doi: 10.2174/1874350101710010190

Canrinus, E., and Fokkens-Bruinsma, M. (2011). "Motivation to become a teacher and its relationships with teaching self-efficacy, professional commitment, and perceptions of the learning environment," in Paper Presented at the 24th International Congress for School Effectiveness and Improvement, (Limassol). 
Caprara, G. V., and Steca, P. (2006). The contribution of self-regulatory efficacy beliefs in managing affect and family relationships to positive thinking and hedonic balance. J. Soc. Clin. Psychol. 25, 603-627. doi: 10.1521/jscp.2006.25. 6.603

Chan, D. W. (2004). Perceived emotional intelligence and self-efficacy among Chinese secondary school teachers in Hong Kong. Pers. Individ. Differ. 36, 1781-1795. doi: 10.1016/j.paid.2003.07.007

Diener, E., and Emmons, R. A. (1984). The independence of positive and negative affect. J. Pers. Soc. Psychol. 47, 1105-1117. doi: 10.1037/0022-3514.47. 5.1105

Diener, E., Larsen, R. J., Levine, S., and Emmons, R. A. (1985). Intensity and frequency. Dimensions underlying positive and negative affect. J. Pers. Soc. Psychol. 48, 1253-1265. doi: 10.1037/0022-3514.48.5.1253

Diener, E., Suh, E. M., Lucas, R. E., and Smith, H. L. (1999). Subjective well-being: three decades of progress. Psychol. Bull. 125, 276-302. doi: 10.1037/0033-2909. 125.2.276

Fiorilli, C., Pepe, A., Buonomo, I., and Albanese, O. (2017). At-risk teachers: the association between burnout levels and emotional appraisal processes. Open Psychol. J. 10, 127-139. doi: 10.2174/1874350101710010127

Fredrickson, B. L. (2001). The role of positive emotions in positive psychology: the broaden-and-build theory of positive emotions. Am. Psychol. 56, 218-226. doi: 10.1037/0003-066X.56.3.218

Fredrickson, B. L., and Losada, M. F. (2005). Positive affect and the complex dynamics of human flourishing. Am. Psychol. 60, 678-686. doi: 10.1037/0003066X.60.7.678

Fredrickson, B. L., Mancuso, R. A., Branigan, C., and Tugade, M. M. (2000). The undoing effect of positive emotions. Motiv. Emot. 24, 237-258. doi: 10.1023/A: 1010796329158

Frenzel, A. C., Pekrun, R., Goetz, T., Daniels, L. M., Durksen, T. L., BeckerKurz, B., et al. (2016). Measuring Teachers' enjoyment, anger, and anxiety: the teacher emotions scales (TES). Contemp. Educ. Psychol. 46, 148-163. doi: 10.1016/j.cedpsych.2016.05.003

Gloria, C. T., Faulk, K. E., and Steinhardt, M. A. (2013). Positive affectivity predicts successful and unsuccessful adaptation to stress. Motiv. Emot. 37, 185-193. doi: 10.1007/s11031-012-9291-8

Goddard, R. D., Hoy, W. K., and Hoy, A. W. (2007). Collective efficacy beliefs: theoretical developments, empirical evidence, and future directions. Educ. Res. 33, 3-13. doi: 10.3102/0013189x033003003

Goetz, T., Becker, E. S., Bieg, M., Keller, M. M., Frenzel, A. C., and Hall, N. C. (2015). The glass half empty: how emotional exhaustion affects the state-trait discrepancy in self-reports of teaching emotions. PLoS One 10:e0137441. doi: 10.1371/journal.pone.0137441

Gonzalez-Calvo, G., and Arias-Carballal, M. (2017). A teacher's personalemotional identity and its reflection upon the development of his professional identity. Qual. Rep. 22, 1693-1709.

González-Calvo, G., and Fernández-Balboa, J. M. (2018). A qualitative analysis of the factors determining the quality of relations between a novice physical education teacher and his students' families: implications for the development of professional identity. Sport Educ. Soc. 23, 491-504. doi: 10.1080/13573322. 2016.1208164

Granziera, H., and Perera, H. N. (2019). Relations among teachers' self-efficacy beliefs, engagement, and work satisfaction: a social cognitive view. Contemp. Educ. Psychol. 58, 75-84. doi: 10.1016/j.cedpsych.2019.02.003

Hayes, A. F. (2012). PROCESS: A Versatile Computational Tool for Observed Variable Mediation, Moderation, and Conditional Process Modeling. Available at: http://www.afhayes.com (accessed June 2019).

Holstein, J. A., and Gubrium, J. F. (2000). Constructing the Life Course. Dix Hills, NY: General Hall.

Jennings, P. A., and Greenberg, M. T. (2009). The prosocial classroom: teacher social and emotional competence in relation to student and classroom outcomes. Rev. Educ. Res. 79, 491-525. doi: 10.3102/003465430832 5693

Kuppens, P., and Van Mechelen, I. (2007). Interactional appraisal models for the anger appraisals of threatened self-esteem, other-blame, and frustration. Cogn. Emot. 21, 56-77. doi: 10.1080/02699930600562193

Llorens, S., Schaufeli, W., Bakker, A., and Salanova, M. (2007). Does a positive gain spiral of resources, efficacy beliefs and engagement exist? Comput. Human Behav. 23, 825-841. doi: 10.1016/j.chb.2004.11.012
Lohbeck, A., Hagenauer, G., and Frenzel, A. C. (2018). Teachers' self-concepts and emotions: conceptualization and relations. Teach. Teach. Educ. 70, 111-120. doi: $10.1016 /$ j.tate.2017.11.001

Lyubomirsky, S., King, L., and Diener, E. (2005). The benefits of frequent positive affect: does happiness lead to success? Psychol. Bull. 131, 803-855. doi: 10.1037/ 0033-2909.131.6.803

Malinen, O. P., and Savolainen, H. (2016). The effect of perceived school climate and teacher efficacy in behavior management on job satisfaction and burnout: a longitudinal study. Teach. Teach. Educ. 60, 144-152. doi: 10.1016/j.tate.2016. 08.012

Maxwell, S. E., and Cole, D. A. (2007). Bias in cross-sectional analyses of longitudinal mediation: partial and complete mediation under an autoregressive model. Psychol. Methods 12, 23-44. doi: 10.1080/00273171.2011. 606716

McDonald, R. P. (1999). Test Theory: A Unified Treatment. Mahwah, NJ: Lawrence Erlbaum Associates.

Mevarech, Z. R., and Maskit, D. (2015). The teaching experience and the emotions it evokes. Soc. Psychol. Educ. 13, 9286-9292. doi: 10.1007/s11218-014-9286-2

Moè, A., Pazzaglia, F., and Friso, G. (2010). MESI - Motivazione, Emozioni, Strategie e Insegnamento. Questionari Metacognitivi per gli insegnanti. Trento: Erickson.

O'Connor, K. E. (2008). "You choose to care": teachers, emotions and professional identity. Teach. Teach. Educ. 24, 117-126. doi: 10.1016/j.tate.2006.11.008

OECD (2014). TALIS 2013 Results: An International Perspective on Teaching and Learning. Paris: OECD.

O’Malley, A. L., and Gregory, J. B. (2011). Don't be such a downer: using positive psychology to enhance the value of negative feedback. Psychol. J. 14, 247-264. doi: 10.1080/10887156.2011.621776

Palmer, P. J. (1998). The Courage to Teach: Exploring the Inner Landscape of a Teacher's Life. San Francisco: Jossey-Bass.

Preacher, K. J., Rucker, D. D., and Hayes, A. F. (2007). Addressing moderated mediation hypotheses: Theory, methods, and prescriptions. Multivariate Behav. Res. 42, 185-227. doi: 10.1080/00273170701341316

Revelle, W. (2016). R Package Psych: Procedures for Psychological, Psychometric, and Personality Research. $R$ package version 1.7.8.

Revelle, W., and Zinbarg, R. E. (2009). Coefficients alpha, beta, omega, and the glb: comments on sijtsma. Psychometrika 74, 145-154. doi: 10.1007/s11336-0089102-z

Roa-Tampe, K. A. (2017). Teacher Evaluation from the standpoint of professional development: the chilean case. Educ. Educ. 20, 41-61. doi: 10.5294/edu.2017.20. 1.3

Rodríguez-Sánchez, A., Salanova, M., Cifre, E., and Schaufeli, W. B. (2011). When good is good: a virtuous circle of self-efficacy and flow at work among teachers. Rev. Psicol. Soc. 26, 427-441. doi: 10.1174/021347411797361257

Santisi, G., Magnano, P., Hichy, Z., and Ramaci, T. (2014). Metacognitive strategies and work motivation in teachers: an empirical study. Proc. Soc. Behav. Sci. 116, 1227-1231. doi: 10.1016/j.sbspro.2014.01.373

Schutz, P. A., and Lee, M. (2014). Teacher emotion, emotional labor and teacher identity. Utr. Stud. Lang. Commun. 27, 169-186.

Staw, B. M., Sutton, R. I., and Pelled, L. H. (2008). Employee positive emotion and favorable outcomes at the workplace. Organ. Sci. 5, 51-71. doi: 10.1287/orsc. 5.1 .51

Sutton, R. E., and Harper, E. (2009). “Teachers' emotion regulation," in International Handbook of Research on Teachers and Teaching, eds L. J. Saha and A. G. Dworkin (Boston, MA: Springer), 389-401. doi: 10.1007/978-0-38773317-3_25

Sutton, R. E., and Wheatley, K. F. (2003). Teachers' emotions and teaching: a review of the literature and directions for future research. Educ. Psychol. Rev. 15, 327-358. doi: 10.1023/A:1026131715856

Thamm, R. A. (2006). “The classification of emotions," in Handbook of the Sociology of Emotions, eds J. E. Stets and J. H. Turner (Boston, MA: Springer), 11-37. doi: 10.1007/978-0-387-30715-2_2

Tracy, J. L., and Robins, R. W. (2007). "The self in self-conscious emotions: a cognitive appraisal approach," in The Self-Conscious Emotions: Theory and Research, eds J. L. Tracy, R. W. Robins, and J. P. Tangney (New York, NY: Guilford Press), 3-20.

Tsai, W. C., Chen, C. C., and Liu, H. L. (2007). Test of a model linking employee positive moods and task performance. J. Appl. Psychol. 92, 1570-1583. doi: 10.1037/0021-9010.92.6.1570 
Tschannen-Moran, M., Hoy, A. W., and Hoy, W. K. (1998). Teacher efficacy: its meaning and measure. Rev. Educ. Res. 68, 202-248. doi: 10.3102/ 00346543068002202

Tugade, M. M., and Fredrickson, B. L. (2004). Resilient individuals use positive emotions to bounce back from negative emotional experiences. J. Pers. Soc. Psychol. 86, 320-333. doi: 10.1037/0022-3514.86.2.320

Tugade, M. M., and Fredrickson, B. L. (2007). Regulation of positive emotions: emotion regulation strategies that promote resilience. J. Happiness Stud. 8, 311-333. doi: 10.1007/s10902-006-9015-4

van der Want, A. C., Schellings, G. L. M., and Mommers, J. (2018). Experienced teachers dealing with issues in education: a career perspective. Teach. Teach. Theory Pract. 24, 802-824. doi: 10.1080/13540602.2018.1481024

Van Veen, K., and Sleegers, P. (2006). How does it feel? Teachers' emotions in a context of change. J. Curric. Stud. 38, 85-111. doi: 10.1080/00220270500109304

Watson, D. (2000). Basic problems in positive mood regulation. Psychol. Inq. 11, 205-209.

Wright, T. A., and Staw, B. M. (1999). Affect and favorable work outcomes: two longitudinal tests of the happy-productive worker thesis. J. Organ. Behav. 20, 1-23. doi: 10.1002/(SICI)1099-1379(199901)20:1<1::AID-JOB885<3.0. $\mathrm{CO} ; 2-\mathrm{W}$

Xanthopoulou, D., Bakker, A. B., Demerouti, E., and Schaufeli, W. B. (2012). A diary study on the happy worker: how job resources relate to positive emotions and personal resources. Eur. J. Work Organ. Psychol. 21, 489-517. doi: 10.1080/ 1359432X.2011.584386

Yin, H.-B., and Lee, J. C. K. (2012). Be passionate, but be rational as well: emotional rules for Chinese teachers' work. Teach. Teach. Educ. 28, 56-65. doi: 10.1016/j. tate.2011.08.005

Zee, M., and Koomen, H. M. Y. (2016). Teacher self-efficacy and its effects on classroom processes, student academic adjustment, and teacher well-being. Rev. Educ. Res. 86, 981-1015. doi: 10.3102/0034654315626801

Zembylas, M. (2003). Emotions and teacher identity: a poststructural perspective. Teach. Teach. Theory Pract. 9, 213-238. doi: 10.1080/1354060030 9378

Conflict of Interest Statement: The authors declare that the research was conducted in the absence of any commercial or financial relationships that could be construed as a potential conflict of interest.

Copyright (c) 2019 Buonomo, Fiorilli and Benevene. This is an open-access article distributed under the terms of the Creative Commons Attribution License (CC BY). The use, distribution or reproduction in other forums is permitted, provided the original author(s) and the copyright owner(s) are credited and that the original publication in this journal is cited, in accordance with accepted academic practice. No use, distribution or reproduction is permitted which does not comply with these terms. 